\title{
Effect of metformin on insulin-stimulated glucose transport in isolated skeletal muscle obtained from patients with NIDDM
}

\author{
D. Galuska, L. A. Nolte, J. R. Zierath, H. Wallberg-Henriksson \\ Department of Clinical Physiology, Karolinska Hospital, Karolinska Institute, Stockholm, Sweden
}

\begin{abstract}
Summary Metformin has been demonstrated to lower blood glucose in vivo by a mechanism which increases peripheral glucose uptake. Furthermore, the therapeutic concentration of metformin has been estimated to be in the order of $0.01 \mathrm{mmol} / \mathrm{l}$. We investigated the effect of metformin on insulin-stimulated 3-0-methylglucose transport in isolated skeletal muscle obtained from seven patients with non-insulindependent diabetes mellitus (NIDDM) and from eight healthy subjects. Whole body insulin-mediated glucose utilization was decreased by $45 \%(p<0.05)$ in the diabetic subjects when studied at $8 \mathrm{mmol} / \mathrm{l} \mathrm{glu}-$ cose, compared to the healthy subjects studied at $5 \mathrm{mmol} / \mathrm{l}$ glucose. Metformin, at concentrations of 0.1 and $0.01 \mathrm{mmol} / 1$, had no effect on basal or insulin-stimulated $(100 \mu \mathrm{U} / \mathrm{ml})$ glucose transport in muscle strips from either of the groups. However, the two control subjects and three patients with NIDDM
\end{abstract}

which displayed a low rate of insulin-mediated glucose utilization $\left(<20 \mu \mathrm{mol} \cdot \mathrm{kg}^{-1} \cdot \mathrm{min}^{-1}\right)$, as well as in vitro insulin resistance, demonstrated increased insulin-stimulated glucose transport in the presence of metfor$\mathrm{min}$ at $0.1 \mathrm{mmol} / 1(p<0.05)$. In conclusion, the concentration of metformin resulting in a potentiating effect on insulin-stimulated glucose transport in insulinresistant human skeletal muscle is 10 -fold higher than the therapeutic concentrations administered to patients with NIDDM. Thus, it is conceivable that the hypoglycaemic effect of metformin in vivo may be due to an accumulation of the drug in the extracellular space of skeletal muscle, or to an effect of the drug distal to the glucose transport step. [Diabetologia (1994) 37: 826-832

Key words Insulin, metformin, 3-0-methylglucose transport, non-insulin-dependent diabetes mellitus.
Glucose utilization in skeletal muscle is a complex, regulated process $[1,2]$, whereby the transport of glucose across the cell membrane is rate limiting under normal physiological conditions $[3,4]$. Peripheral

Received: 23 December 1993

and in revised form: 31 March 1994

Corresponding author: Dr. H. Wallberg-Henriksson, Department of Clinical Physiology, Karolinska Hospital, S-171 76 Stockholm, Sweden

Abbreviations: NIDDM, Non-insulin-dependent diabetes mellitus; KHB, Krebs-Henseleit's bicarbonate buffer; HEPES, N-2 hydroxyethyl-piperazine-N'-2-ethanesulfonic acid; BSA, bovine serum albumin; RIA, radioimmunoassay; $\mathrm{HbA}_{1 \mathrm{c}}$, glycated haemoglobin $A_{1}$; BMI, body mass index $\left(\mathrm{kg} / \mathrm{m}^{2}\right)$; GLUT 1 , HepG2/erythrocyte; GLUT 4, insulin-regulatable glucose transporter. insulin resistance, and decreased whole body glucose utilization are common characteristic features of patients with NIDDM and/or obesity [5, 6]. The impairment in whole body glucose utilization demonstrated in NIDDM patients has been partly attributed to the muscular glucose transport step [7, 8]. Among the oral antidiabetic agents typically prescribed to patients with NIDDM, metformin has emerged as an effective blood glucose lowering drug used for the treatment of peripheral insulin resistance [9]. Amelioration of hyperglycaemia by metformin treatment in patients with NIDDM appears to be due to an enhanced insulin-mediated glucose metabolism in peripheral tissues [10]. Although metformin does not augment insulin secretion from the pancreas $[11,12]$, a low endogenous production of insulin is required to obtain an optimal 
Table 1. Clinical and biochemical data of the subjects

\begin{tabular}{llllccc}
\hline Group & $n$ & $\begin{array}{l}\text { Age } \\
(\text { years })\end{array}$ & $\begin{array}{l}\text { BMI } \\
\left(\mathrm{kg} / \mathrm{m}^{2}\right)\end{array}$ & $\begin{array}{l}\text { Plasma glucose } \\
(\mathrm{mmol} / 1)\end{array}$ & $\begin{array}{l}\text { Serum insulin } \\
(\mu \mathrm{U} / \mathrm{ml})\end{array}$ & $\begin{array}{l}\mathrm{HbA}_{1 \mathrm{c}} \\
(\%)\end{array}$ \\
\hline Healthy subjects & 8 & $51 \pm 3$ & $24.8 \pm 0.7$ & $5.0 \pm 0.2$ & $5.4 \pm 1.0$ & $4.0 \pm 0.1$ \\
NIDDM patients & 7 & $51 \pm 2$ & $27.7 \pm 1.3$ & $11.7 \pm 1.3^{\mathrm{a}}$ & $18.3 \pm 2.7^{\mathrm{a}}$ & $7.7 \pm 0.5^{\mathrm{a}}$ \\
\hline
\end{tabular}

Values are presented as mean \pm SEM. ${ }^{a} p<0.05$ vs healthy subjects

effect of the drug in vivo [13]. Collectively, these observations suggest that the in vivo effect(s) of metformin may have a direct influence upon insulin action and skeletal muscle glucose uptake in patients with NIDDM.

Previously we have reported that metformin, in a concentration of $0.1 \mathrm{mmol} / 1$, normalizes the decreased capacity for insulin-mediated glucose transport in insulin-resistant human skeletal muscle when tested under euglycaemic conditions [14]. Nevertheless, the therapeutic concentration of metformin has been estimated to be in the order of $0.01 \mathrm{mmol} / \mathrm{l}$ [15], and the majority of patients with NIDDM demonstrate chronic hyperglycaemia. Thus, the aim of the present study was to test the hypothesis that metformin corrects a defect at the level of glucose transport in insulin-resistant skeletal muscle exposed to a hyperglycaemic environment. For this purpose we employed an open muscle biopsy technique [16] to obtain intact skeletal muscle from patients with NIDDM, and from healthy subjects. The viability of this muscle strip preparation for in vitro studies has been demonstrated previously by independent groups $[8,16,17]$.

\section{Subjects and methods}

Subject characteristics: The study participants consisted of seven patients with NIDDM and eight healthy subjects. All participants were male, and were matched for age. The clinical and metabolic data of the subjects are presented in Table 1 . All of the NIDDM patients were treated with oral anti-hyperglycaemic agents (sulphonylurea). In addition to the sulphonylurea-treatment, two patients received metformin, and one patient was receiving insulin treatment. No evidence of any other metabolic disturbance was identified in the diabetic patients. None of the healthy subjects received any medication known to affect glucose metabolism, and none of the participants were smokers. All of the participants were studied following a 12-h fast. One healthy subject, and one patient with NIDDM did not participate in the hyperinsulinaemic-euglycaemic clamp investigation. The present investigation was approved by the Ethical Committee of the Karolinska Institute, and informed consent was received from all of the study participants.

Muscle strip preparation and 3-0-methylglucose transport determinations: We have utilized a muscle biopsy technique to obtain intact human skeletal muscle suitable for in vitro investigations [8]. Following administration of local anaesthesia (mevipakain $5 \mathrm{mg} / \mathrm{ml}$ ), two large muscle samples $(\sim 300 \mathrm{mg} /$ sample) were excised from the lateral portion of the quadriceps femoris muscle as previously described [16]. The muscle specimens were immediately placed in oxygenated, ice cold KHB [18] supplemented with $5 \mathrm{mmol} / 1 \mathrm{HEPES}, 0.1 \% \mathrm{BSA}$ (RIA grade), $5 \mathrm{mmol} / \mathrm{l}$ pyruvate, $5 \mathrm{mmol} / \mathrm{l}$ glutamate and $4 \mathrm{mmol} / \mathrm{l}$ succinate. From the larger specimen, smaller muscle specimens were dissected free $(\sim 18 \mathrm{mg})$, mounted on plexiglass clamps, as described previously [8] and were subsequently incubated in vitro in KHB media $(10 \mathrm{~min})$ in individual glass flasks placed in a shaking waterbath $\left(60\right.$ times $/ \mathrm{min}$, at $\left.35^{\circ} \mathrm{C}\right)$. The gas phase in the flasks was maintained with $95 \% \mathrm{O}_{2} /$ $5 \% \mathrm{CO}_{2}$. Thereafter, the muscle strips were transferred to a fresh KHB media containing an addition of insulin, or metformin as described in the figures and tables, and incubated for $2 \mathrm{~h}$. The muscle strips were incubated in a near ambient glucose concentration; $5 \mathrm{mmol} / 1$ glucose for control and $8 \mathrm{mmol} / 1$ glucose for diabetic muscle strips. Mannitol was added to the KHB media to maintain a constant osmolarity $(40 \mathrm{mmol} / \mathrm{l})$ in the presence of the varying glucose concentrations. Prior to exposure to the glucose analogue, 3-0-methylglucose, the muscle strips were exposed to a glucose free media $(10 \mathrm{~min})$ in order to rinse glucose from the extra-cellular space. Thereafter, the muscle specimens were transferred to final incubation media (20 min), whereby ${ }^{3}[\mathrm{H}] 3-0$-methylglucose $(347 \mu \mathrm{Ci} /$ $\mathrm{mmol})$ and ${ }^{14}[\mathrm{C}]$ mannitol $(8 \mu \mathrm{Ci} / \mathrm{mmol})$ were present at a concentration equal to that of the glucose and mannitol, respectively. Preliminary work from our laboratory indicates that the rate of 3-0-methylglucose transport in the presence of $8 \mathrm{mmol} / \mathrm{l}$ glucose and $100 \mu \mathrm{U} / \mathrm{ml}$ insulin remains linear for $\sim 35 \mathrm{~min}$ (J.R.Zierath and H. Wallberg-Henriksson un published results), thus, no counter transport of 3-0-methylglucose occurred during the 20 -min radioactive incubation period. The insulin and metformin concentrations were maintained throughout all incubations. Upon termination of the radioactive incubation, the muscle strips were frozen in liquid nitrogen and processed as described by Wallberg-Henriksson et al. [19]. The 3-0-methylglucose transport measurements are expressed per $\mathrm{ml}$ of intra-cellular water.

Hyperinsulinaemic-euglycaemic clamp technique: Whole body insulin-mediated peripheral glucose utilization was evaluated by the hyper-insulinaemic-euglycaemic clamp technique [20]. Under local anaesthesia, one catheter was inserted in the brachial artery for blood sampling and a second catheter was inserted in a forearm vein for insulin and glucose infusion. After obtaining baseline blood samples, a glucose infusion was initiated $\left(1 \mathrm{mg} \cdot \mathrm{kg}^{-1} \cdot \mathrm{min}^{-1}\right)$ and a bolus insulin dose was administered $\left(24 \mathrm{nmol} \cdot \mathrm{kg}^{-1} \cdot \mathrm{min}^{-1}\right.$ for an inital $2 \mathrm{~min}$, followed by $12 \mathrm{nmol} \cdot \mathrm{kg}^{-1} \cdot \mathrm{min}^{-1}$ for $\left.6 \mathrm{~min}\right)$. Thereafter, a continuous insulin infusion was given $\left(6 \mathrm{nmol} \cdot \mathrm{kg}^{-1} \cdot \mathrm{min}^{-1}\right)$. A steady-state plasma glucose concentration was maintained for $100 \mathrm{~min}$ $(5 \times 20 \mathrm{~min})$ at fasting levels (approximately 5 or $8 \mathrm{mmol} / \mathrm{l}$ for healthy subjects or NIDDM patients, respectively) by means of a variable glucose infusion rate. The actual plasma glucose concentration was measured at 5 -min intervals by the glucose oxidase method (Beckman Glucose Analyzer II Fullerton, Calif. USA). Blood samples for analysis of whole blood glucose and serum insulin levels during steady-state were taken every $30 \mathrm{~min}$. The mean glucose utilization was determined from the glucose infusion rate during the $100 \mathrm{~min}(5 \times 20 \mathrm{~min})$ steady- 


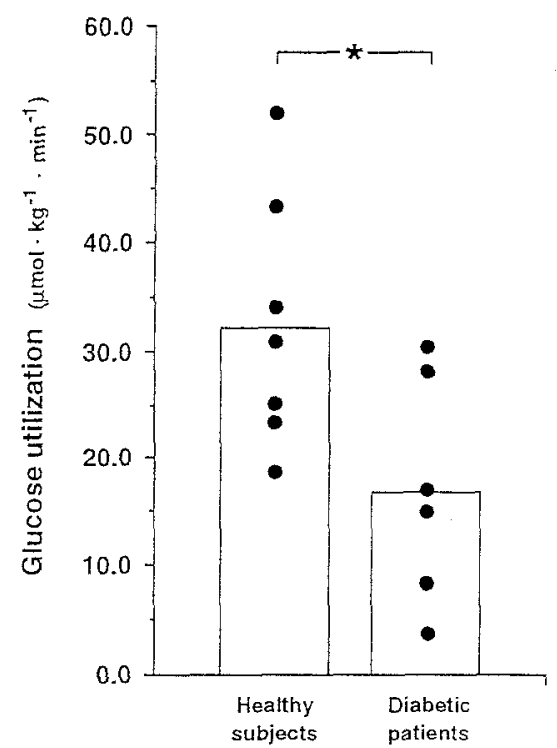

Fig. 1. Rate of insulin-mediated whole body glucose utilization measured during steady-state conditions for $100 \mathrm{~min}$, with a plasma glucose concentration of $4.8 \pm 0.1 \mathrm{mmol} / 1$ for the healthy subjects and $7.3 \pm 0.4 \mathrm{mmol} / \mathrm{l}$ for the NIDDM patients. The mean steady-state serum insulin level was significantly higher in the NIDDM patient group $(73.8 \pm 2.6 \mu \mathrm{U} / \mathrm{ml})$ compared to that of the healthy subjects $(67.0 \pm 2.4 \mu \mathrm{U} / \mathrm{ml})$ $(p<0.05)$. Values are presented as mean \pm SEM. $* p<0.05$ vs healthy subjects

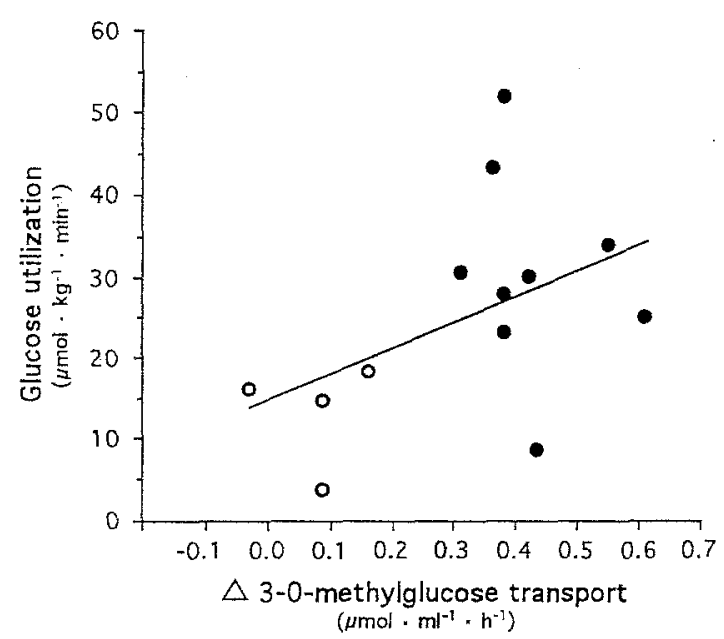

Fig.2. Correlation between insulin-mediated whole body glucose utilization and the insulin-stimulated 3-0-methylglucose transport rate above basal in insulin sensitive (๑) and insulinresistant $(0)$ muscles from patients with NIDDM and healthy subjects $r=0.48, p<0.1$ (equation $y=34.10 x+14.37$ ). One healthy subject and one diabetic patient are not included in the correlation since no glucose utilization data could be obtained from these subjects

state conditions. All values were corrected for the glucose abundance, or loss in the intracellular space.

Assays and chemicals: The glucose concentration in arterial blood obtained during the clamp was determined by the glucose dehydrogenase method using a glucose reagent kit assay (Merck, Darmstadt, Germany). Serum insulin was determined by a standard radioimmunoassay (Phadeseph Insulin RIA method, Pharmacia, Uppsala, Sweden). $\mathrm{HbA}_{1 \mathrm{c}}$, as a percentage of total blood haemoglobin, was determined at constant room temperature $\left(23^{\circ} \mathrm{C}\right)$ by using a commercially available kit (BioRad Laboratories, Richmond, Calif., USA). The reference value for $\mathrm{HbA}_{1 \mathrm{c}}$ in our laboratory is less than $5.5 \%$. Unless specifically stated, all chemicals were obtained from Sigma Chemical Company (St. Louis, Mo., USA). The isotopes were purchased from New England Nuclear (Boston, Mass., USA.). Insulin Actrapid $100 \mathrm{IE} / \mathrm{ml}$ (human) was a product of Novo Nordisk A/ $S$ (Copenhagen, Denmark) and Metformin was a generous gift from Lipha (Lyon, France).

\section{Statistical analysis}

A one-way analysis of variance (ANOVA) was used to assess statistical differences between groups. When the ANOVA resulted in a significant $F$-value, the difference between the means was identified by the Fisher PLSD post hoc test. Student's unpaired $t$-test was used when comparisons between two mean values were made. Results are expressed as means \pm SEM.

\section{Results}

Whole body insulin-mediated glucose uptake in vivo: Insulin-mediated glucose utilization was assessed by the hyperinsulinaemic-euglycaemic clamp technique. During the clamp procedure, a steady-state plasma glucose concentration was maintained for $100 \mathrm{~min}$ at a near ambient fasting blood glucose level. The mean level during five 20 -min periods was $4.8 \pm 0.1 \mathrm{mmol} / 1$ for the healthy subjects and $7.3 \pm 0.4 \mathrm{mmol} / 1$ for the NIDDM patients. Despite a significantly higher steady-state serum insulin level in the NIDDM patients $(73.8 \pm 2.6 \mu \mathrm{U} / \mathrm{ml})$ compared with that of the healthy subjects $(67.0 \pm 2.4 \mu \mathrm{U} / \mathrm{ml})(p<0.05)$, the mean glucose infusion rate (glucose utilization) was markedly lower in the NIDDM patients $\left(16.9 \pm 4.3 \mu \mathrm{mol} \cdot \mathrm{kg}^{-1}\right.$ - $\mathrm{min}^{-1}$ ) when compared to the healthy subjects $\left(30.7 \pm 4.2 \mu \mathrm{mol} \cdot \mathrm{kg}^{-1} \cdot \mathrm{min}^{-1}\right)$ (Fig.1). The insulinmediated whole body glucose utilization demonstrated a weak, positive correlation with the insulinstimulated rate of 3-0-methylglucose transport measured at the muscular level in the NIDDM patients and the healthy subjects ( $R=0.48, p<0.1$; Fig. 2$)$. In four of the subjects, insulin-resistance was evident based upon the low rate of in vivo whole body insulinmediated glucose utilization and the diminished response of the skeletal muscle glucose transport process to insulin (Fig. 2).

Effect of metformin on 3-0-methylglucose transport: The basal rate of 3-0-methylglucose transport, measured in skeletal muscle obtained from the patients with NIDDM and the healthy subjects, was unaltered by metformin $(0.1 \mathrm{mmol} / \mathrm{l})$ (Table 2$)$. Nevertheless, basal 3-0-methylglucose transport was slightly, but not significantly, elevated in the diabetic muscles as a response to the hyperglycaemic environment ( 8 vs 
Table 2. Effect of metformin on basal and insulin-stimulated 3-0-methylglucose transport in in vitro incubated muscles obtained from healthy subjects and patients with NIDDM

\begin{tabular}{|c|c|c|c|c|c|c|}
\hline \multirow[t]{2}{*}{ Group } & \multirow[b]{2}{*}{$n$} & \multicolumn{2}{|l|}{ Basal } & \multicolumn{3}{|c|}{ Insulin $100 \mu \mathrm{U} / \mathrm{ml}$} \\
\hline & & No metformin & $\begin{array}{l}\text { Metformin } \\
(0.1 \mathrm{mmol} / \mathrm{l})\end{array}$ & No metformin & $\begin{array}{l}\text { Metformin } \\
(0.01 \mathrm{mmol} / \mathrm{l})\end{array}$ & $\begin{array}{l}\text { Metformin } \\
(0.1 \mathrm{mmol} / \mathrm{l})\end{array}$ \\
\hline Healthy subjects & 8 & $0.63 \pm 0.13$ & $0.74 \pm 0.12$ & $1.00 \pm 0.12$ & $0.98 \pm 0.14$ & $\begin{array}{l}1.14 \pm 0.23^{a} \\
1.38 \pm 0.16\end{array}$ \\
\hline
\end{tabular}

Values are presented as mean \pm SEM. ${ }^{a} p<0.05$ vs basal, no metformin

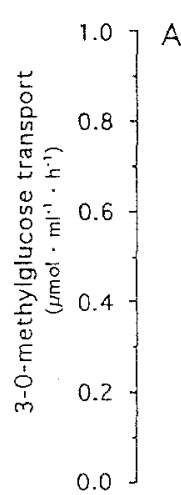

Metformin

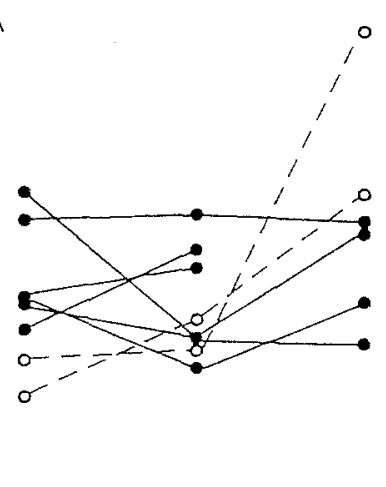

0

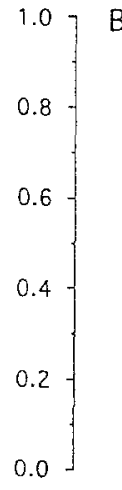

$0.1 \mathrm{mmol} /$

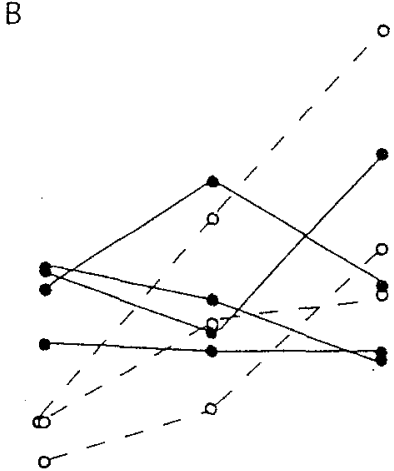

$0.01 \mathrm{mmol}$

$0.1 \mathrm{mmol} / \mathrm{s}$
Fig. 3. A, B Effect of metformin on the individual insulin-stimulated $(100 \mu \mathrm{U} / \mathrm{ml})$ of 3-0-methylglucose transport rate above basal transport in incubated skeletal muscle strips obtained from healthy control individuals (A) and NIDDM patients (B). The open circles denote the subjects which were classified as insulin resistant
$5 \mathrm{mmol} / \mathrm{l}$ 3-0-methylglucose). Insulin, at a concentration of $100 \mu \mathrm{U} / \mathrm{ml}$, did not significantly alter the basal rate of the 3-0-methylglucose transport in the muscle strips obtained from the healthy subjects. The insulinstimulated rate of 3-0-methylglucose transport $(100 \mu \mathrm{U} / \mathrm{ml})$ measured in the muscle strips obtained from the diabetic patients did not differ from that observed in the muscle specimens obtained from the healthy subjects (Table 2). Metformin at 0.1 or $0.01 \mathrm{mmol} / \mathrm{l}$ did not alter the insulin-stimulated rate of 3-0-methylglucose transport in the skeletal muscle specimens obtained from the NIDDM patients (Table 2).

Individual responses for the effect of metformin on insulin-stimulated 3-0-methylglucose transport: The aim of the present study was to test the hypothesis that metformin normalizes a defect in cellular glucose metabolism at the level of glucose transport. This hypothesis can only be tested if the study group demonstrates a significant decrease in insulin action on glucose transport. Regardless of whether the subjects were categorized as a healthy control group, (Fig. $3 \mathrm{a}$ ) or as a diabetic group (Fig. 3 b), both groups displayed a wide response of the skeletal muscle glucose transport to insulin. However, when the three NIDDM patients which displayed the lowest in vitro and in vivo response to insulin (Fig. 3) were taken together with the two control subjects with the lowest in vitro response to insulin, these subjects collectively demonstrated a $63 \%(p<0.05)$ increase in in vitro insulinstimulated glucose transport in isolated skeletal mus- cle strips following exposure to $0.1 \mathrm{mmol} / 1$ metformin. Conversely, no significant potentiating effect of metformin was noted on insulin-mediated 3-0-methylglucose transport in these skeletal muscle strips following exposure to $0.01 \mathrm{mmol} / \mathrm{l}$ of metformin. No differences between these subjects and the rest of the participants were noted in BMI, or fasting plasma glucose and serum insulin levels.

\section{Discussion}

Insulin action on glucose transport is markedly impaired in skeletal muscle obtained from lean [7] and obese [8] patients with NIDDM. This defect appears to be due to an altered distribution or activation of the insulin regulatable glucose transporter, GLUT 4, in muscle cells from lean and moderately obese diabetic patients $[21,22]$. The present study was undertaken to test the hypothesis that metformin can correct the defect in insulin action on glucose transport in skeletal muscle obtained from patients with NIDDM. Thus, one would only expect an effect of metformin in muscles which demonstrate an impairment in the capacity for insulin-stimulated glucose transport. Since only three of the seven patients with NIDDM demonstrated muscular insulin-resistance at the cellular level, it was not surprising that metformin did not alter insulin-action on the muscular glucose transport process in the NIDDM group. Because of the heterogeneity of the in vitro responses to insulin displayed by the participants, the individual data was assessed with 
respect to the five most insulin-resistant participants (three patients with NIDDM and two control subjects). With this approach, we could confirm our earlier finding of a potentiating effect of metformin on insulin action in insulin-resistant human skeletal muscle [14]. However, the potentiating effect of metformin was only noted when muscle strips were exposed to $0.1 \mathrm{mmol} / \mathrm{l}$ metformin.

Based on measurements of circulating levels of metformin measured $2 \mathrm{~h}$ after an oral dose $(0.5-1.0 \mathrm{~g} /$ day), the therapeutic level of metformin has been estimated to be in the order of $0.01 \mathrm{mmol} / 1$ [15]. In the present study, $0.01 \mathrm{mmol} / \mathrm{l}$ of metformin did not significantly alter insulin-stimulated glucose transport in the insulin-resistant subjects. The blood glucose lowering effect of metformin observed in vivo, has been attributed to a potentiating effect on insulin-mediated glucose utilization, primarily on skeletal muscle [10]. However, if the hypoglycaemic effect of the drug is primarily an effect at the level of glucose transport, an accumulation of metformin is likely to occur in vivo, at the cellular surface.

Our results suggest that the muscular glucose transport step per se may not be the primary site of action for the in vivo effect of metformin at a concentration of $0.01 \mathrm{mmol} / \mathrm{l}$. Our findings are in accordance with those of a recent study by Handberg et al. [23], which demonstrate that chronic metformin treatment does not normalize the decreased GLUT 4 content in skeletal muscle of obese (fa/fa) Zucker rats. Metformin, at a concentration of $0.06 \mathrm{mmol} / \mathrm{l}$, has been suggested to act at the level of glucose transport in isolated rat adipocytes by potentiating the insulininduced translocation of GLUT 1 and GLUT 4 to the plasma membrane from an intracellular domain [24]. Furthermore, the down-regulation of GLUT 4 at the plasma membrane in connection with insulin treatment, has been demonstrated to be prevented by exposing $24 \mathrm{~h}$ insulin-treated rat adipocytes to $1 \mathrm{mmol} / \mathrm{l}$ metformin [25]. Furthermore, lower concentrations of metformin did not block the down-regulation of cell surface content of GLUT 4 caused by chronic insulin treatment of rat adipocytes [25]. Thus, it appears that the effect of metformin on the cellular glucose transport step is concentration dependent.

There are several alternative explanations for the blood glucose lowering effect of metformin which is observed in the in vivo situation. Patients with NIDDM display alterations in both oxidative and nonoxidative glucose metabolism [26], thus, it is possible that metformin corrects a defect distal to the glucose transport process. Consequently, metformin might improve the reduced glycogen synthase activity which has been noted in skeletal muscle of NIDDM patients [27]. In soleus muscle obtained from streptozotocin diabetic mice, therapeutic concentrations of metformin have been demonstrated to increase insulin-induced glycogen synthase activity by $30 \%$ [28]. Fur- thermore, in skeletal muscle of diabetic mice, metformin has been shown to improve hexokinase activity in the absence of insulin [28], increase glucose oxidation in response to maximal insulin-stimulating concentrations [28], and enhance insulin-stimulated glycolysis [29].

Two of the participants in the present study were treated with metformin in conjunction with sulphonylurea treatment. One of these two patients displayed an in vitro response to insulin which was $78 \%$ above the basal glucose transport rate, and skeletal muscle strips from this particular patient did not respond to any of the two metformin concentrations tested. In contrast, the other patient receiving metformin treatment demonstrated whole body (in vivo) and cellular (in vitro) insulin-resistance. The skeletal muscle strips from this patient demonstrated a response to metformin which paralleled that of the other insulin-resistant subjects. However, since the pretreated degree of insulin resistance in these two subjects is not known, we cannot rule out the possibility of a chronic effect of metformin treatment on skeletal muscle glucose transport.

We have previously demonstrated that skeletal muscle obtained from patients with NIDDM exhibit a decreased dose-response relationship for insulinstimulated 3-0-methylglucose transport in vitro when incubated in glucose free media [7]. In the present study, when muscle strips from the patients with NIDDM were incubated in $8 \mathrm{mmol} / \mathrm{l}$ glucose, the glucose transport capacity was similar to that of the muscle strips obtained from the healthy subjects, incubated in the presence of $5 \mathrm{mmol} / 1$ glucose. This effect can be attributed to the mass-action of glucose $[30,31]$. Potentially, the up-regulated glucose transport capacity demonstrated by the muscle strips from the patients with NIDDM might limit a possible potentiating effect of metformin. However, this interpretation seems unlikely since muscle strips from three of the diabetic patients were incubated in the presence of $8 \mathrm{mmol} / \mathrm{l}$ glucose and did respond to the in vitro exposure of metformin. Thus, our results indicate that the potentiating effect of $0.1 \mathrm{mmol} / 1 \mathrm{met}-$ formin on insulin-stimulated glucose transport at the cellular level is not dependent on the level of glycaemia, but rather on the presence of insulin resistance.

A weak positive, but not significant, correlation between the insulin-induced increase of 3-0-methylglucose transport and the whole body insulin-mediated glucose utilization was observed in the patients with NIDDM and the healthy subjects. Nevertheless, those patients which demonstrated the lowest insulin mediated peripheral glucose utilization rates in vivo also demonstrated a marked insulin resistance in vitro. However, the protocol employed for the hyperinsulinaemic-euglycaemic clamp might not have been sufficient to suppress the endogenous glucose pro- 
duction in the subjects which displayed the lowest glucose utilization rates. Consequently, the glucose utilization rates reported for these subjects might have been moderately underestimated. The lack of a significant insulin-stimulated increase in the rate of 3-0methylglucose transport in the skeletal muscle strips from the healthy subjects appears to be a reflection of the ageing process and a progressive development of insulin-resistance. Utilizing the same in vitro technique, we have observed a 2-3-fold stimulation of 3-0methylglucose transport in skeletal muscle samples from younger (<35 years) individuals $[16$, J.R.Zierath and H. Wallberg-Henriksson unpublished observation].

In conclusion, metformin at a concentration of $0.1 \mathrm{mmol} / 1$ exerts a potentiating effect on insulin-stimulated glucose transport in insulin-resistant skeletal muscle, irrespective of the presence of diabetes. Nevertheless, a therapeutic concentration of metfor$\mathrm{min}, 0.01 \mathrm{mmol} / \mathrm{l}[15]$, did not significantly alter the capacity for insulin-stimulated glucose transport in the insulin-resistant group. Consequently, the in vivo blood glucose lowering effect of metformin could possibly be explained by an accumulation of metformin in the muscular extracellular space, or by an effect of the drug at a step distal to that of glucose transport.

Acknowledgements. This study was supported by grants from the Swedish Medical Research Council (5117), the Bank of Sweden Tercentenary Foundation, the Swedish Diabetes Association, the Nordisk Insulin Foundation, the Thuring Foundation, the Wiberg Research Foundation, Gustav V's Research Foundation, and from Novo-Nordisk A/S. JR Zierath was supported by a fellowship from the Swedish Medical Research Council (10627).

\section{References}

1. Bell GI, Kayano T, Buse JB et al. (1990) Molecular biology of mammalian glucose transporters. Diabetes Care 13: 198208

2. Klip A, Pâquet MR (1990) Glucose transport and glucose transporters in muscle and their metabolic regulation. Diabetes Care 13: 228-243

3. Wallberg-Henriksson H (1987) Glucose transport into skeletal muscle. Influence of contractile activity, insulin, catecholamines and diabetes mellitus. Acta Physiol Scand 131 [Suppl 564]: 1-80

4. Ziel FH, Venkatesan N, Davidson MB (1988) Glucose transport is rate limiting for skeletal muscle glucose metabolism in normal and STZ-induced diabetic rats. Diabetes 37: $885-890$

5. Olefsky JM, Garvey WT, Henry RR, Brillon D, Mathaei S, Freidenberg GR (1988) Cellular mechanisms of insulin resistance in non-insulin-dependent (type II) diabetes. Am J Med 85 [Suppl 5A]: 86-105

6. Caro JF, Dohm LG, Pories WJ, Sindha MK (1989) Cellular alterations in liver, skeletal muscle and adipose tissue responsible for insulin resistance in obesity and type $\Pi$ diabetes. Diabetes Metab Rev 5: 665-689

7. Andreasson K, Galuska D, Thörne A, Sonnenfeld T, Wallberg-Henriksson H (1991) Decreased insulin-stimulated 3-
0 -methylglucose transport in in vitro incubated muscle strips from type II diabetic subjects. Acta Physiol Scand 142: 255-260

8. Dohm GL, Trapscot EB, Pories WJ et al. (1988) An in vitro muscle preparation suitable for metabolic studies. J Clin Invest 82: 486-494

9. Herman LS (1979) Metformin: a review of its pharmacological properties and therapeutic use. Diabete Metab 5: 233245

10. Hother-Nielsen O, Schmitz O, Andersen PH, Beck-Nielsen $\mathrm{H}$, Pedersen O (1989) Metformin improves peripheral but not hepatic insulin action in obese patients with type II diabetes. Acta Endocrinol 120: 257-265

11. Jackson RA, Hawa MI, Jaspan JB et al. (1987) Mechanism of metformin action in non-insulin-dependent diabetes. Diabetes 36: 632-640

12. Wu MS, Johnston P, Sheu VHH et al. (1990) Effect of metformin on carbohydrate and lipoprotein metabolism in NIDDM patients. Diabetes Care 13: 1-8

13. Sterne J (1969) Pharmacology and mode of action of hypoglycaemic guanidine derivatives. In: Campell GD (ed) Oral hypoglycaemic agents. Academic Press, London, UK, pp 193-245

14. Galuska G, Zierath JR, Thörne A, Sonnenfeld T, WallbergHenriksson H (1991) Metformin increases insulin-stimulated glucose transport in insulin resistant human skeletal muscle. Diabete Metab 17: 59-63

15. Bailey CJ (1992) Biguanides and NIDDM. Diabetes Care 15: 755-772

16. Zierath JR, Galuska D, Engström $\AA$ et al. (1992) Human islet amyloid polypeptide at pharmacological levels inhibits insulin and phorbol-ester-stimulated glucose transport in in vitro incubated human muscle strips. Diabetologia 35: 2631

17. Argyraki M, Wright PD, Venables CW, Proud G, Taylor R (1989) In vitro study of human skeletal muscle strips: effect of nonesterified fatty acid supply on glucose storage. Metabolism 38: 1183-1187

18. Krebs HA, Henseleit K (1932) Untersuchungen über die Harnstoffbildung im Tierkörper. Hoppe-Steyler's Z Physiol Chem 210: 33-66

19. Wallberg-Henriksson H, Zetan N, Henriksson J (1987) Reversibility of decreased insulin-stimulated glucose transport capacity in diabetic muscle with in vitro incubation. $\mathrm{J}$ Biol Chem 262: 7665-7671

20. De Fronzo RA, Tobin JD, Andres R (1979) Glucose clamp technique: a method for quantifying insulin secretion and resistance. Am J Physiol 173: E214-E223

21. Pedersen O, Bak JF, Andersen PH et al. (1990) Evidence against altered expression of GLUT 1 and GLUT 4 in skeletal muscle of patients with obesity or NIDDM. Diabetes 39: $865-870$

22. Vogt B, Mühlbacher C, Carrascossa J et al. (1992) Subcellular distribution of Glut 4 in skeletal muscle of lean type 2 (non-insulin-dependent) diabetic patients in the basal state. Diabetologia 35: 456-463

23. Handberg A, Kayser L, Hoyer PE, Voldstedlund M, Hansen HP, Vinten J (1993) Metformin ameliorates diabetes but does not normalize the decreased GLUT 4 content in skeletal muscle of obese (fa/fa) Zucker rats. Diabetologia 36: 481-486

24. Matthaei S, Hamann A, Klein HH, Benecke H, Kreymann G, Flier JS, Greten H (1991) Association of metformin's effect to increase insulin-stimulated glucose transport with potentiation of insulin-induced translocation of glucose transporters from an intracellular pool to plasma membrane in rat adipocytes. Diabetes 40: 850-857 
25. Kozzka IJ, Holman GD (1993) Metformin blocks downregulation of cell surface GLUT 4 caused by chronic insulin treatment of adipocytes. Diabetes 42: 1159-1165

26. Garvey WT (1989) Insulin resistance and noninsulin-dependent diabetes mellitus: which horse is pulling the cart? Diabetes Metab Rev 5: 727-742

27. Beck-Nielsen H, Vaag A, Damsbo P et al. (1992) Insulin resistance in skeletal muscles in patients with NIDDM. Diabetes Care 15: $418-429$

28. Bailey CJ, Puah JA (1986) Effect of metformin on glucose metabolism in mouse soleus muscle. Diabete Metab 12: 212-218
29. Lord JM, Puah JA, Atkins TW, Bailey CJ (1985) Postreceptor effect of metformin on insulin action in mice. $J$ Pharm Pharmacol 37: 821-823

30. Yki-Järvinen H (1992) Glucose toxicity. Endocr Rev 13: 415-431

31. Henry RR, Gumbiner B, Flynn T, Thorburn AW (1990) Metabolic effects of hyperglycemia and hyperinsulinemia on the fate of intracellular glucose in NIDDM. Diabetes 39: $149-156$ 